\title{
Practical consensus guidelines for the management of enuresis
}

\author{
Johan Vande Walle • Soren Rittig • Stuart Bauer • \\ Paul Eggert • Daniela Marschall-Kehrel • Serdar Tekgul
}

Received: 25 November 2011 / Accepted: 25 January 2012 /Published online: 24 February 2012

(C) The Author(s) 2012. This article is published with open access at Springerlink.com

\begin{abstract}
Despite the high prevalence of enuresis, the professional training of doctors in the evaluation and management of this condition is often minimal and/or inconsistent. Therefore, patient care is neither optimal nor efficient, which can have a profound impact on affected children and their families. Once comprehensive history taking and evaluation has eliminated daytime symptoms or comorbidities, monosymptomatic enuresis can be managed efficaciously in the majority of patients. Non-monosymptomatic enuresis is often a more complex condition; these patients may benefit from referral to specialty care centers. We outline two alternative strategies to determine the most appropriate course of care. The first is a basic assessment covering only the essential components of diagnostic investigation which can be carried out in one office visit. The second strategy includes several additional evaluations including completion of a voiding diary, which requires extra time during the initial consultation and two office visits
\end{abstract}

\footnotetext{
J. Vande Walle

Pediatric Nephrology Unit, Ghent University Hospital,

Ghent, Belgium

S. Rittig

Department of Pediatrics, Aarhus University Hospital,

Skejby, Denmark

e-mail: soren.rittig@skejby.rm.dk

S. Bauer

Department of Urology, Children's Hospital,

Harvard Medical School,

Boston, MA, USA

e-mail: stuart.bauer@childrens.harvard.edu

P. Eggert

University Children's Hospital,

Kiel, Germany

e-mail: p.eggert@pediatrics.uni-kiel.de
}

before treatment or specialty referral is provided. This should yield greater success than first-line treatment. Conclusion: This guideline, endorsed by major international pediatric urology and nephrology societies, aims to equip a general pediatric practice in both primary and secondary care with simple yet comprehensive guidelines and practical tools (i.e., checklists, diary templates, and quick-reference flowcharts) for complete evaluation and successful treatment of enuresis.

Keywords Enuresis $\cdot$ Monosymptomatic $\cdot$ Consensus guidelines $\cdot$ Primary care $\cdot$ Management

\section{Introduction}

Evaluation and management of enuresis, a common condition, is not a priority in training programs for medical

\author{
D. Marschall-Kehrel \\ Urology Consultancy, \\ Frankfurt/Main, Germany \\ e-mail: kehrel.daniela@t-online.de
}

S. Tekgul

Department of Urology, Hacettepe University School of Medicine,

Ankara, Turkey

e-mail: tekgul-k@tr.net

\author{
J. Vande Walle $(\bowtie)$ \\ Pediatric Nephrology UZ Ghent, \\ De Pintelaan 185, \\ 9000 Ghent, Belgium \\ e-mail: johan.vandewalle@uzgent.be
}


doctors (MDs), despite being a common condition. Frequent bedwetting (defined as $>3$ wet nights per week) has an estimated prevalence of nearly $10 \%$ in children aged 7 years $[9,16,17,22,57]$ and is associated with embarrassment and significant emotional and practical difficulties for affected children and their families. Information available to families on the internet is often inaccurate, while guidelines for doctors are often center- or subdiscipline-dependent and are published in highly specific specialty journals not available to the majority of MDs in primary or secondary pediatric care [13, 18, 24, 33, 37, 41, 46, 47]. No unifying set of recommendations for a diagnostic and management algorithm of enuresis currently exists.

\section{Aims of this paper}

This manuscript aims to present an international consensus on a practical, rational approach to the diagnosis and management of bedwetting in the primary care setting. Recommendations are based on the International Children's Continence Society (ICCS) standardization document on monosymptomatic enuresis (MNE) [31], empirical evidence, and discussions of leading experts in pediatric urology and nephrology during a consensus meeting in 2009. The recommendations have been reviewed and endorsed by committees representing the American Academy of Pediatrics, European Society for Paediatric Urology (ESPU), European Society for Paediatric Nephrology, and the ICCS.

This guideline is intended as a practical supplement to the recent ICCS standardization report [31] and provides direction and tools (e.g., checklists, flowcharts, and diaries) for MDs to use in children with enuresis and their parents, by outlining minimum evaluation criteria, initial treatment options, and indications for referral to a specialist center/doctor.

\section{Background}

Box 1: Terminology
Definitions
Comorbidity factors: Factors proven to be associated with increased
incidence of enuresis and/or increased therapy resistance
Expected bladder capacity (EBC): Calculated as [30+(age in years $\times$
30)] in milliliters
Maximum voided volume (MVV): The largest volume of urine voided
in a 24-h period, as documented in a bladder diary kept over
$3-4$ days, excluding first morning voids
Conditions

Enuresis: Intermittent incontinence while asleep in a child $>5$ years of age Monosymptomatic enuresis: Enuresis with no other lower urinary tract symptoms
Nocturnal polyuria (NP): Overproduction of urine at night, defined as nocturnal urine output exceeding $130 \%$ of EBC for age

Non-monosymptomatic enuresis: Enuresis with other, mainly daytime, lower urinary tract symptoms

Overactive bladder (OAB): all children with complaints of urgency and frequency with or without incontinence

A full glossary of all relevant terminology and definitions can be found in the 2006 ICCS standardization paper [33]

The pathophysiology of enuresis is complex, involving the central nervous system (several neurotransmitters and receptors), circadian rhythm (sleep and diuresis), and bladder function derangements. A simplified screening process enables identification of two archetypes of enuresis:

- Underlying NP associated with low overnight vasopressin levels [38], decreased urinary osmolality, and poor likelihood of a desmopressin response

- "Small for age" bladder volume associated with OAB (overlaps with subtype of non-monosymptomatic enuresis (NMNE) - patients with lower urinary tract symptoms), reduced desmopressin response, and higher rates of response to the enuresis alarm

A combination of both forms is possible, and such patients generally respond well to combined therapy with desmopressin and an alarm. In addition to these urinary/ bladder storage characteristics, all children with enuresis experience impaired arousal from sleep which prevents waking to void in the toilet $[25,32]$.

In children aged $\geq 5$ years, enuresis is considered abnormal. Reasons for proactive management include the distress caused to child and family, difficulty of "sleeping over" on holiday or at friends' houses, social withdrawal, reduced self-esteem [12], and potential disturbance of the child's and the parents' sleep architecture that may have an impact on daytime functioning and health $[5,7,23,60]$. Moreover, untreated enuresis (especially if severe) can persist indefinitely, with prevalence rates in adulthood of $2-3 \%[61,63]$. As such, prompt therapy may avoid serious consequences for the child's well-being. Additional reasons include the risk that some parents may be intolerant of their child's wetting [3, 43, 55] and the significant inconvenience and costs associated with frequent laundering of bedsheets and clothing $[34,44]$. The lack of public awareness that this is a treatable condition means that some families prefer to keep it a secret, hoping for spontaneous resolution, rather than seeking medical help [2].

Children who wet the bed, especially those with severe enuresis, are likely to benefit from appropriately timed treatment; the $2-3 \%$ who continues to wet into early adulthood without treatment may be prevented from enduring the prolonged impact of the incontinence $[20,27,30,34,45]$. 


\section{Management of enuresis}

This clinical management tool (CMT) should help to:

- Raise awareness

- Provide current information to affected families and MDs

- Override false advice and misinformation from unregulated sources

- Limit recommendations to evidence-based treatment strategies

In primary care, "trial and error" treatment for enuresis is often the rule rather than the exception; this approach is a waste of time and money and increases frustration among families and doctors. It may also have an adverse psychological effect on the child [48]. We believe the rational therapeutic approach outlined in the ICCS standardization document [31] would lead to higher success rates.

Specialists have more time to perform a full diagnostic evaluation that may result in improved outcomes than primary care physicians, due to restrictions in time and budget that limit protocol adherence in every affected child. We also recognize that there may be country- and centerspecific variations in the level of investigation possible. Therefore, we propose two levels of evaluation, allowing MDs to choose an appropriate strategy.

Box 2: Strategies for evaluating patients with enuresis in primary care Strategy 1: Minimal evaluation, covering only the essential components of diagnostic investigation during a single office visit that includes evaluation and treatment or referral to a consultant or specialty center

Strategy 2: All components of strategy 1 as well as a small number of additional evaluations that may require extra time during the initial consultation and two office visits before treatment or referral is provided. This probably carries a greater chance of successful first-line treatment

If the chosen strategy is not successful, the child should be referred to a specialist who can provide a more in-depth evaluation of the problem. Flowcharts summarizing the recommended evaluation of patients with enuresis (strategies 1 and 2) are shown in Fig. 1.

\section{Basic evaluation process}

History taking-for strategies 1 and 2

Thorough history taking is an essential component for strategies 1 and 2. A checklist CMT, with footnotes explaining the relevance of each area of questioning and consequences for potential referral, is provided (Table 1) to assist with this process. Essential areas of questioning are listed with more detailed questions to elicit further information when necessary. Although the CMT is designed to be completed by the doctor, it could be adapted as a "self-assessment" test for patients/parents and given to families beforehand to reduce consultation time $[11,15]$.

Physical examination

A brief but thorough physical examination should be performed primarily to identify rare underlying anatomical (phimosis and labial agglutination) or neurogenic (spinal malfunction) causes. Relevant observations are listed in Table 2. Use of urodynamic studies, X-ray, and cystoscopy are not appropriate in this setting; if indicated based on data collected, the family should be referred to a specialist.

\section{Patients with explicit NMNE}

A consensus opinion advocates that daytime symptoms be treated before the enuresis is addressed as coexisting bladder dysfunction is associated with less favorable outcomes for both desmopressin and alarm therapy. Specialist referral is almost mandatory. Children with these findings are considered complex, and their management is controversial and outside the framework of this paper since little evidencebased medicine to guide treatment exists. Furthermore, therapy resistance is likely, and many of the proposed therapies require off-label use of medication.

Patients with constipation

Enuresis (especially NMNE) often occurs concomitantly with constipation. Constipation should therefore be identified and treated before managing enuresis (see Box 3-the Rome criteria).

Box 3: Rome III criteria for diagnosis of constipation [35]

At least two of the following criteria must be met for $\geq 2$ months before diagnosis:

(a) $\leq 2$ defecations in the toilet per week

(b) $\geq 1$ episode of fecal incontinence per week

(c) History of retentive posturing or excessive volitional stool retention

(d) History of painful or hard bowel movements

(e) Presence of a large fecal mass in the rectum

(f) History of large diameter stools that may obstruct the toilet

Patients should not have a diagnosis of irritable bowel syndrome

Other comorbidities

Eating and drinking habits should be reviewed. Helpful advice based on opinion rather than empirical evidence includes avoiding excessive fluids in the evening [24], avoiding caffeinated beverages (expert opinion), ensuring adequate fluid intake during the daytime, avoiding a high 
Fig. 1 Flowcharts

summarizing recommended evaluation of children with enuresis. a Strategy $1=$ minimal; b Strategy $2=$ optimal. CMT clinical management tool, $M N E$ monosymptomatic enuresis, $M V V$ maximum voided volume, $N P$ nocturnal polyuria a

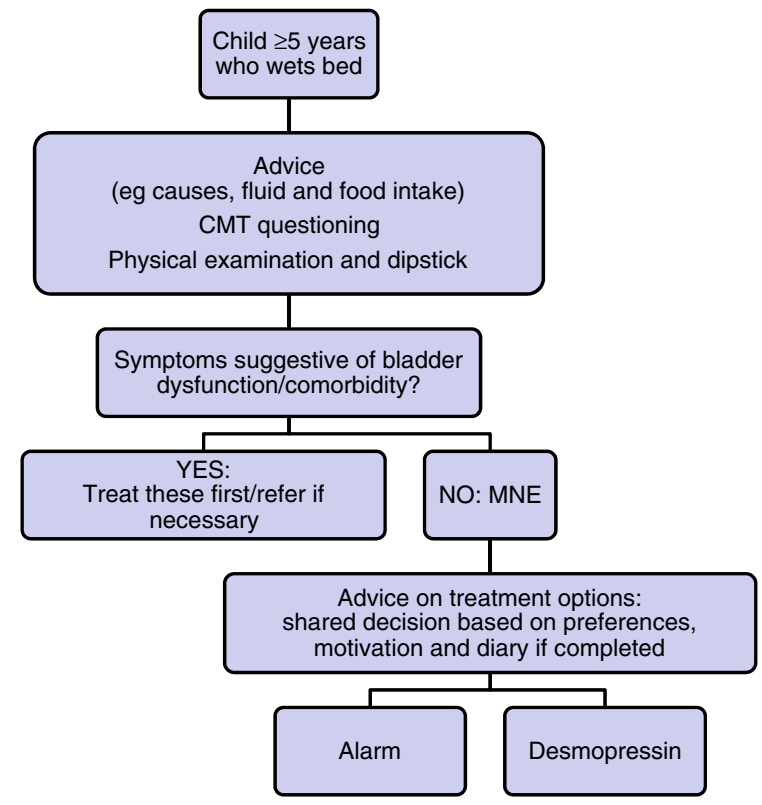

b

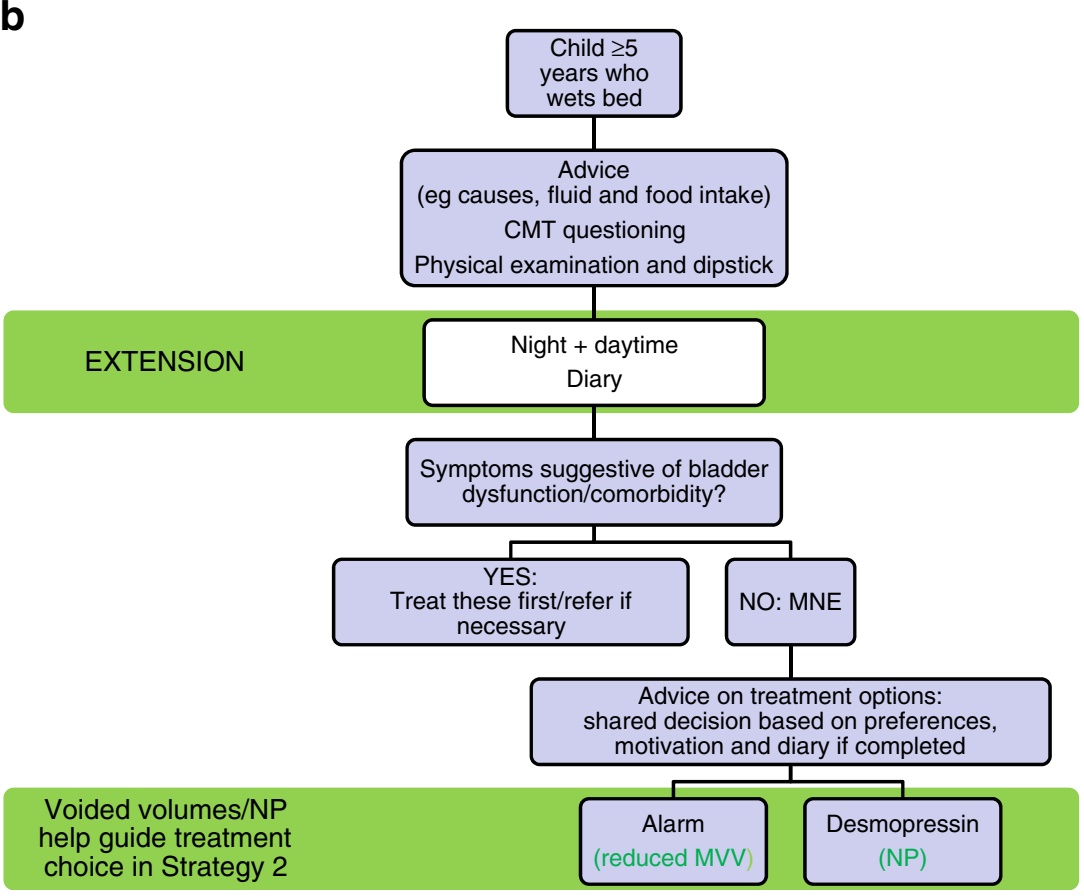

protein diet or salt in the evening (as these induce solute diuresis) [53], and remembering to void before bedtime.

Discussion and reassurance

Paramount to the success of this process is an explanation at the outset of why these measures can be helpful. Children and families should be educated about the condition and reassured that (a) it is a common problem that they should not be embarrassed, (b) it likely affects other members of their peer group, and (c) there are effective treatments to resolve it. Frank discussion should be encouraged and educational materials provided for children and parents to help engage the whole family in the treatment process. Empathetic support should be provided if enuresis persists.

\section{Additional evaluations for strategy 2}

Patient recall does not always correspond with actual voiding patterns. Where possible, it is ideal to provide families 
Table 1 Checklist clinical management tool (CMT)

\begin{tabular}{|c|c|c|c|}
\hline \multirow{2}{*}{$\begin{array}{l}\text { Signs and symptoms } \\
\text { Nocturnal enuresis }\end{array}$} & \multicolumn{2}{|c|}{$\begin{array}{l}\text { Presencel } \\
\text { absence }\end{array}$} & \multirow{2}{*}{$\begin{array}{l}\text { Consider } \\
\text { referral if } \\
\text { positive (R) }\end{array}$} \\
\hline & Yes & No & \\
\hline $\begin{array}{l}\text { Does the child wet the bed? } \\
\text { - Number of nights per week }\end{array}$ & Yes & No & \\
\hline \multicolumn{4}{|l|}{ Establishes severity, which is suggestive of prognosis } \\
\hline Age $\geq 5$ years & Yes & No & \\
\hline \multicolumn{4}{|l|}{$\begin{array}{l}\text { Younger patients are likely to experience spontaneous resolution without intervention; } \\
\text { treatment only considered in children } \geq 5 \text { years }\end{array}$} \\
\hline \multicolumn{4}{|l|}{ Symptoms suggestive for underlying bladder dysfunction } \\
\hline $\begin{array}{l}\text { Leakages of urine during the day } \\
\text { - Drops of urine in the underpants } \\
\text { - Before voiding } \\
\text { - } \quad \text { After voiding } \\
\text { - Frequency of leakage }(\mathrm{N}=\text { episodes per day) } \\
\text { - Intermittent or continuous leakage every day? } \\
\text { - History of daytime incontinence over } 31 / 2 \text { years of age }\end{array}$ & Yes & No & $\mathrm{R}$ \\
\hline \multicolumn{4}{|l|}{ Suggestive of overactive bladder/NMNE } \\
\hline Urinary frequency (\# of voids) ( $\geq 8 \mathrm{x} /$ day)? & Yes & No & $\mathrm{R}$ \\
\hline \multicolumn{4}{|l|}{ Suggestive of overactive bladder } \\
\hline Voiding postponement (\# of voids) ( $\leq 3 \mathrm{x} /$ day)? & Yes & No & $\mathrm{R}$ \\
\hline \multicolumn{4}{|l|}{ Suggestive of dysfunctional voiding } \\
\hline Sudden and urgent need to urinate? & Yes & No & $\mathrm{R}$ \\
\hline \multicolumn{4}{|l|}{ Suggestive of overactive bladder } \\
\hline $\begin{array}{l}\text { Holding maneuvers observed (e.g. Vincent's curtsey - pressing heel } \\
\text { into perineum, leg crossing, standing on tiptoes) }\end{array}$ & Yes & No & $\mathrm{R}$ \\
\hline \multicolumn{4}{|l|}{ Suggestive of dysfunctional voiding } \\
\hline $\begin{array}{l}\text { Needs to push in order to urinate, i.e. need to use abdominal muscles } \\
\text { to strain to pass urine? }\end{array}$ & Yes & No & $\mathrm{R}$ \\
\hline \multicolumn{4}{|l|}{ Suggestive of dysfunctional voiding } \\
\hline Interrupted urinary stream, or several voids, one after another? & Yes & No & $\mathrm{R}$ \\
\hline \multicolumn{4}{|l|}{ Suggestive of dysfunctional voiding } \\
\hline History of urinary tract infection? & Yes & No & $\mathrm{R}$ \\
\hline \multicolumn{4}{|l|}{ Often associated with underlying bladder dysfunction } \\
\hline $\begin{array}{l}\text { Illness and/or malformation? } \\
\text { - Of kidneys and/or urinary tract } \\
\text { - Of spinal cord }\end{array}$ & $\begin{array}{l}\text { Yes } \\
\text { Yes }\end{array}$ & $\begin{array}{l}\text { No } \\
\text { No }\end{array}$ & $\begin{array}{l}R \\
R\end{array}$ \\
\hline \multicolumn{4}{|l|}{ Comorbidity - factors that might predict therapy resistance } \\
\hline $\begin{array}{l}\text { Bowel movements - presence or history of the following? } \\
\text { - Constipation ( } \leq 3 \text { bowel movements/week) } \\
\text { Traces of feces in the underpants (fecal incontinence) - not due } \\
\text { to insufficient wiping of the bottom? }\end{array}$ & Yes & No & $\begin{array}{l}\text { See Box } 3 ; \\
\text { may be } \\
\text { treated in } \\
\text { primary care }\end{array}$ \\
\hline \multicolumn{4}{|l|}{ May predict treatment resistance; resolution of constipation may resolve enuresis } \\
\hline $\begin{array}{l}\text { Psychological, behavioral or psychiatric problems? } \\
\text { - Evidence of ADHD, ADD, autism, etc }\end{array}$ & Yes & No & $\mathrm{R}$ \\
\hline \multicolumn{4}{|l|}{ May predict treatment resistance } \\
\hline \multicolumn{4}{|l|}{ History of motor and/or learning disabilities or delayed development } \\
\hline \multicolumn{4}{|l|}{ Delayed development may be suggestive of central nervous system pathology } \\
\hline \multicolumn{4}{|l|}{ Drinking habits } \\
\hline $\begin{array}{l}\text { - Quantity and type of fluid intake? } \\
\text { - Drinks more than one glass during the evening? } \\
\text { - Drinks during the night? }\end{array}$ & $\begin{array}{l}\text { Yes } \\
\text { Yes }\end{array}$ & $\begin{array}{l}\text { No } \\
\text { No }\end{array}$ & \\
\hline \multicolumn{4}{|l|}{$\begin{array}{l}\text { Water turnover in children is reported to be } 1500 \mathrm{ml} / \mathrm{m}^{2} \text { body surface area per day }{ }^{42} \\
\text { Fluid intake in the evening (after the evening meal) should be minimized since } \\
\text { increased fluid intake results in higher dieresis volumes during the night } \\
\text { Fluid intake during the night should be avoided }\end{array}$} \\
\hline $\begin{array}{l}\text { Exclude diabetes mellitus (dipstick test) } \\
\text { Psychogenic polydipsia poses risk for wat }\end{array}$ & & & \\
\hline
\end{tabular}

Notes for physicians are given in gray text

of child with no apparent symptoms of NMNE with bladder diaries (see template) for completion before a second appointment (evidence level 3, grade B). This has the advantage of helping to distinguish MNE from NMNE and to give important information on bladder capacity and nocturnal urine production. 
Table 2 Important physical examination and urinary test findings in children with enuresis

\begin{tabular}{|c|c|c|}
\hline Strategy & Observation/test & To check for \\
\hline 1 (minimal) & Body weight and height & $\begin{array}{l}\text { Growth retardation and/or failure to thrive suggestive of an } \\
\text { underlying disorder }\end{array}$ \\
\hline 1 (minimal) & Genital examination — including examination of underwear & $\begin{array}{l}\text { Physical abnormalities: hypospadias, phimosis, labial } \\
\text { agglutination. Signs of fecal incontinence }\end{array}$ \\
\hline 1 (minimal) & Inspection of lumbosacral spine & $\begin{array}{l}\text { Occult spinal dysraphism: dimple, lipoma, hypertrichosis, } \\
\text { or sacral agenesis }\end{array}$ \\
\hline 1 (minimal) & Urine dipstick test & $\begin{array}{l}\text { Glycosuria, infection (leucocyturia, nitrite test), hematuria, } \\
\text { and proteinuria }\end{array}$ \\
\hline 2 (extended evaluation) & Rectal palpation if acceptable for child, parent/care giver & $\begin{array}{l}\text { Fecal masses; left bowel palpation may be more acceptable } \\
\text { to family }\end{array}$ \\
\hline \multirow[t]{2}{*}{2 (extended evaluation) } & $\begin{array}{l}\text { Neurological examination (size, tight heel cords, hammer, } \\
\text { or claw toes) }\end{array}$ & $\begin{array}{l}\text { Signs and symptoms suggestive of lower spinal cord } \\
\text { dysfunction }\end{array}$ \\
\hline & $\begin{array}{l}\text { The neurologic exam should include assessment of } \\
\text { posturing with a stress gait or mirror movements }\end{array}$ & CNS abnormalities suggestive of a central cause \\
\hline
\end{tabular}

CNS central nervous system

Diary recommendations:

1. Daytime diary used to assess the child's bladder capacity (see Template 1). Measurement of MVV (excluding the first morning void) needs to be made over a minimum of 3-4 days for accuracy; weekends or school holidays are ideal [21]. Any leakage of urine during the day as well as fluid intake volumes should also be recorded. The relevance of fluid intake volumes for treatment/advice is not proven, but is included to ensure maximum usability.

2. Bedwetting diary completed for seven consecutive days/nights (Template 2) to assess for the presence of NP. The volume of first morning void (in milliliters) must be added to the difference in diaper weight to calculate nighttime urine production. In patients with nocturia, the volume of nighttime voids should be added; (see Box 1 and Table 3 for values by age). NP should only be anticipated on wet nights [39].

- Bowel movements should be recorded to provide additional information regarding presence of constipation.

Families should be provided with a vessel for collecting and measuring urine volumes (e.g., $20 \mathrm{ml}$ increments), and, if needed, diapers or pull-ups which can be weighed. The importance of completing both diaries for ascertaining the cause and likely most successful treatment should be explained.

Although no randomized studies have compared the outcome of strategies 1 and 2, there is significant evidence of the predictive value of both MVV and NP for outcomes with most common treatment modalities.

Template 1 Daytime diary over two consecutive weekends

\begin{tabular}{|c|c|c|c|c|c|c|c|c|c|c|c|c|c|c|c|}
\hline \multicolumn{4}{|c|}{ Saturday (weekend 1) } & \multicolumn{4}{|c|}{ Sunday (weekend 1) } & \multicolumn{4}{|c|}{ Saturday (weekend 2) } & \multicolumn{4}{|c|}{ Sunday (weekend 2) } \\
\hline Time & $\begin{array}{l}\text { Volume } \\
\text { of } \\
\text { drinks } \\
(\mathrm{mL}) \\
\end{array}$ & $\begin{array}{l}\text { Volume } \\
\text { of urine } \\
(\mathrm{mL})\end{array}$ & $\begin{array}{l}\text { Leakage } \\
\text { of urine } \\
\text { ( } \checkmark \text { or } x \text { ) }\end{array}$ & Time & \begin{tabular}{|l|}
$\begin{array}{l}\text { Volume } \\
\text { of } \\
\text { drinks } \\
(\mathrm{mL})\end{array}$ \\
\end{tabular} & $\begin{array}{l}\text { Volume } \\
\text { of urine } \\
(\mathrm{mL})\end{array}$ & $\begin{array}{l}\text { Leakage } \\
\text { of urine } \\
\text { ( } \checkmark \text { or } x \text { ) }\end{array}$ & Time & $\begin{array}{l}\text { Volume } \\
\text { of } \\
\text { drinks } \\
(\mathrm{mL}) \\
\end{array}$ & $\begin{array}{l}\text { Volume } \\
\text { of urine } \\
(\mathrm{mL})\end{array}$ & $\begin{array}{l}\text { Leakage } \\
\text { of urine } \\
\text { ( } \checkmark \text { or } x \text { ) }\end{array}$ & Time & \begin{tabular}{|l} 
Volume \\
of \\
drinks \\
$(\mathrm{mL})$ \\
\end{tabular} & $\begin{array}{l}\text { Volume } \\
\text { of urine } \\
\text { (mL) }\end{array}$ & $\begin{array}{l}\text { Leakage } \\
\text { of urine } \\
\text { ( } \checkmark \text { or } x \text { ) }\end{array}$ \\
\hline & & & & & & & & & & & & & & & \\
\hline & & & & & & & & & & & & & & & \\
\hline & & & & & & & & & & & & & & & \\
\hline & & & & & & & & & & & & & & & \\
\hline & & & & & & & & & & & & & & & \\
\hline & & & & & & & & & & & & & & & \\
\hline & & & & & & & & & & & & & & & \\
\hline & & & & & & & & & & & & & & & \\
\hline & & & & & & & & & & & & & & & \\
\hline & & & & & & & & & & & & & & & \\
\hline & & & & & & & & & & & & & & & \\
\hline & & & & & & & & & & & & & & & \\
\hline & & & & & & & & & & & & & & & \\
\hline & & & & & & & & & & & & & & & \\
\hline
\end{tabular}

From this information, the most important observation for the clinician is the maximum voided volume. The largest urinated volume should be identified. It should be considered abnormally small or large if found to be $<65 \%$ or $>150 \%$ of expected bladder capacity (EBC), respectively [6] - see Table 2 listing EBC, reduced MVV, large MVV and NP values for 5-18 years 
Template 2 Overnight diary for seven consecutive nights

\begin{tabular}{|c|c|c|c|c|c|c|c|}
\hline & Monday & Tuesday & Wednesday & Thursday & Friday & Saturday & Sunday \\
\hline $\begin{array}{l}\text { Time I went to } \\
\text { bed last night }\end{array}$ & & & & & & & \\
\hline Time I got up & & & & & & & \\
\hline Dry night* & & & & & & & \\
\hline Wet night $^{\star \star}$ & & & & & & & \\
\hline $\begin{array}{l}\text { I got up in the } \\
\text { night to pee. If } \\
\text { yes, record } \\
\text { volume }\end{array}$ & & & & & & & \\
\hline $\begin{array}{l}\text { In the } \\
\text { morning, my } \\
\text { diaper } \\
\text { weighed (g) }\end{array}$ & & & & & & & \\
\hline $\begin{array}{l}\text { The volume of } \\
\text { my first pee in } \\
\text { the morning } \\
(\mathrm{mL})\end{array}$ & & & & & & & \\
\hline $\begin{array}{l}\text { Pooed today } \\
\text { (yes/no) }\end{array}$ & & & & & & & \\
\hline $\begin{array}{l}\text { Doctor to } \\
\text { complete this } \\
\text { row } \\
\text { Nocturnal } \\
\text { urine } \\
\text { production } \\
\text { [urine volume } \\
+ \text { change in } \\
\text { diaper weight] }\end{array}$ & & & & & & & \\
\hline
\end{tabular}

${ }^{a}$ Dry night is when you do not wet your bed or your diaper

${ }^{\mathrm{b}}$ Wet night is when you wet your bed or your diaper

\section{Guidance for using enuresis therapies}

Monosymptomatic enuresis

MNE can be effectively treated by a general practitioner (Fig. 2). Two first-line treatment options are availabledesmopressin and enuresis alarm. Their initial selection should be guided by the family's level of motivation and their preference (strategy 1). Information from diaries (strategy 2) will identify one of four subtypes of MNE and allow further fine-tuning of treatment according to the child's characteristics and family motivation.

1. Children with a normal urine output during the night and normal bladder capacity can be given either the alarm or desmopressin.

2. Children with smaller than expected bladder capacity for age will likely be desmopressin-resistant and more sensitive to the alarm.

3. Children with NP and normal bladder volume will be more sensitive to desmopressin.

4. Children with both excessive urine output and reduced bladder capacity may find combined therapy of alarm and desmopressin to be successful [26]. This strategy lessens the burden of alarm treatment as the alarm is triggered several times per night.

\section{Desmopressin therapy}

Desmopressin is a synthetic analog of arginine vasopressin, the naturally occurring antidiuretic hormone. One of its major actions is to reduce the volume of urine produced overnight to within normal limits. Desmopressin has a level 1 , grade A recommendation from the International Consultation on Incontinence (ICI) in 2009 [46]. It is available as a tablet (dosage, $0.2-0.6 \mathrm{mg}$ ) or a fast-melting oral lyophilisate (Melt; dosage, 120-360 $\mu \mathrm{g}$ ). The latter is a recommended formulation for all children [6] and is preferred by children under 12 years [28]. It is not affected by nasal congestion or gastrointestinal transit and does not require fluid intake. Since tablets require up to $200 \mathrm{ml}$ of fluid intake, which is $\sim 25 \%$ of a 7 -year-old's bladder capacity, the Melt formulation is more suited to the antidiuretic indication of desmopressin [40]. Good pharmacodynamic data are available for the Melt and its dosing in children with enuresis [54]. 
Table 3 Expected age-related bladder capacity and interpretation of maximum and total voided volume overnight (all in milliliters), EBC calculated as: $[30+($ age in years $\times 30)]$ in milliliters

\begin{tabular}{llll}
\hline Age (years) & BC (ml) & $\begin{array}{l}\text { MVV below listed } \\
\text { volume }=\text { reduced } \\
\text { bladder capacity; } \\
\text { consider alarm }\end{array}$ & $\begin{array}{l}\text { Total volume below } \\
\text { listed value }=\text { nocturnal } \\
\text { polyuria; consider } \\
\text { desmopressin }\end{array}$ \\
\hline 5 & 180 & 117 & 234 \\
6 & 210 & 137 & 273 \\
7 & 240 & 156 & 312 \\
8 & 270 & 176 & 351 \\
9 & 300 & 195 & 390 \\
10 & 330 & 215 & 429 \\
11 & 360 & 234 & 468 \\
12 & 390 & 254 & 507 \\
13 & 390 & 254 & 507 \\
14 & 390 & 254 & 507 \\
15 & 390 & 254 & 507 \\
16 & 390 & 254 & 507 \\
17 & 390 & 254 & 507 \\
18 & 390 & 254 & 507 \\
\hline
\end{tabular}

A pronounced nocturnal arginine vasopressin deficiency is seen in desmopressin responders only on nights with enuresis - therefore, NP should only be looked for on wet nights [41]. Excessive nocturnal urinary volumes indicated by diary data and various additional signs are suggestive of underlying NP [43, 62], e.g., absorbent underpants totally soaked overnight, urine soaking through to the bedsheets, multiple episodes of wetting in one night, early wetting in the first third of the night, a large volume of urine at the first void in the morning despite wetting overnight, a low daytime fluid intake followed by the majority of the intake in the late afternoon and evening

$M V V$ maximum voided volume, $E B C$ expected bladder capacity, $N P$ nocturnal polyuria

Medication should be taken $1 \mathrm{~h}$ before the last void before bedtime to allow timely enhanced concentration of urine to occur. Fluid intake should be reduced from $1 \mathrm{~h}$ before desmopressin administration and for $8 \mathrm{~h}$ subsequently to encourage optimal concentrating capacity and treatment response, as well as to reduce the risk of hyponatremia/water intoxication.

Desmopressin is only effective on the night of administration; therefore, it must be taken on a daily basis. Full adherence is required to avoid wet nights. Desmopressin acts immediately, but in our expert opinion, the initial duration of treatment should be for 2-6 weeks, to ascertain its anti-enuretic effect. If a sufficient degree of improvement is experienced, then treatment can be continued for an additional 3 months - where appropriate, country-specific regulations regarding treatment breaks should be followed. If patients are dry on treatment after this initial period, breaks are recommended to ascertain whether the problem has resolved and therapy is no longer necessary. If the child does not achieve complete dryness, or if wetting resumes once treatment is withdrawn, it should be continued/resumed. There is some evidence that structured withdrawal of medication may reduce relapse rates following its discontinuation $[4,29]$. If a second voiding diary indicates nocturnal urinary production is not reduced, consider a dose increase (if maximum recommended dose has not been reached); otherwise, refer the child to a specialist.

Desmopressin is well tolerated, but clinicians should be aware that it is a potent antidiuretic and families must be educated regarding the rare possibility of patients developing hyponatremia/water intoxication with symptoms including headache, nausea, and vomiting. Self-titration of medication should be avoided.

\section{Enuresis alarm}

Enuresis alarms have a level 1, grade A ICI recommendation [45]. The alarm is triggered when a sensor in the sheets or night clothes becomes wet, setting off an auditory signal causing the child to wake, cease voiding, and arise to void. Parents are advised to wake their child when the alarm is activated - otherwise, children are prone to turn it off and go back to sleep.

The alarm should be worn every night. Response is not immediate and treatment should be continued for $2-$ 3 months or until the child is dry for 14 consecutive nights (whichever comes first). There may be cultural differences in its acceptability, as it may be highly disruptive for the household and may require a significant commitment of time and effort. The family must be motivated and adhere to this therapy if it is to be successful so they should be preemptively apprised of likely difficulties, but assured the first few weeks are the most troublesome. Doctors should monitor the child's progress early to address any problems and facilitate adherence. The response rate is high in families who continue treatment for a sufficient period, with relatively low relapse rates (though lasting cure rate is still $<50 \%$ ) [19]. Poor compliance and early withdrawal from treatment are common $[14,56,58]$, which may exacerbate parental intolerance. For these reasons, alarm treatment may not be suitable for some families; the clinician should exercise judgment as to whether alarm therapy is appropriate. In cases where the child or his or her family is reluctant to accept the alarm, desmopressin is the alternative [59].

\section{Importance of adherence to the management plan}

It is estimated that $\sim 30 \%$ of non-responders are not taking medication correctly $[1,50]$. Non-adherence to recommendations regarding timing of medication, voiding before 
Fig. 2 First-line treatment options for monosymptomatic enuresis ( $\mathbf{a}$ alarm and $\mathbf{b}$ desmopressin) a

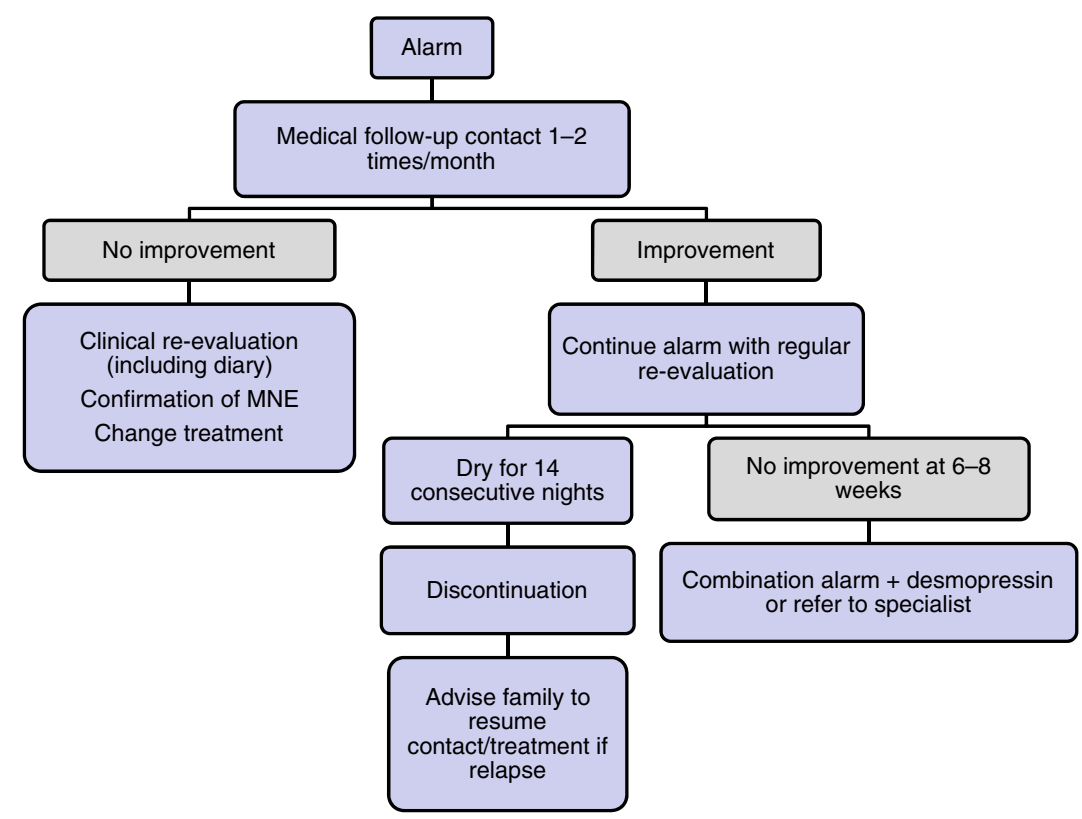

b

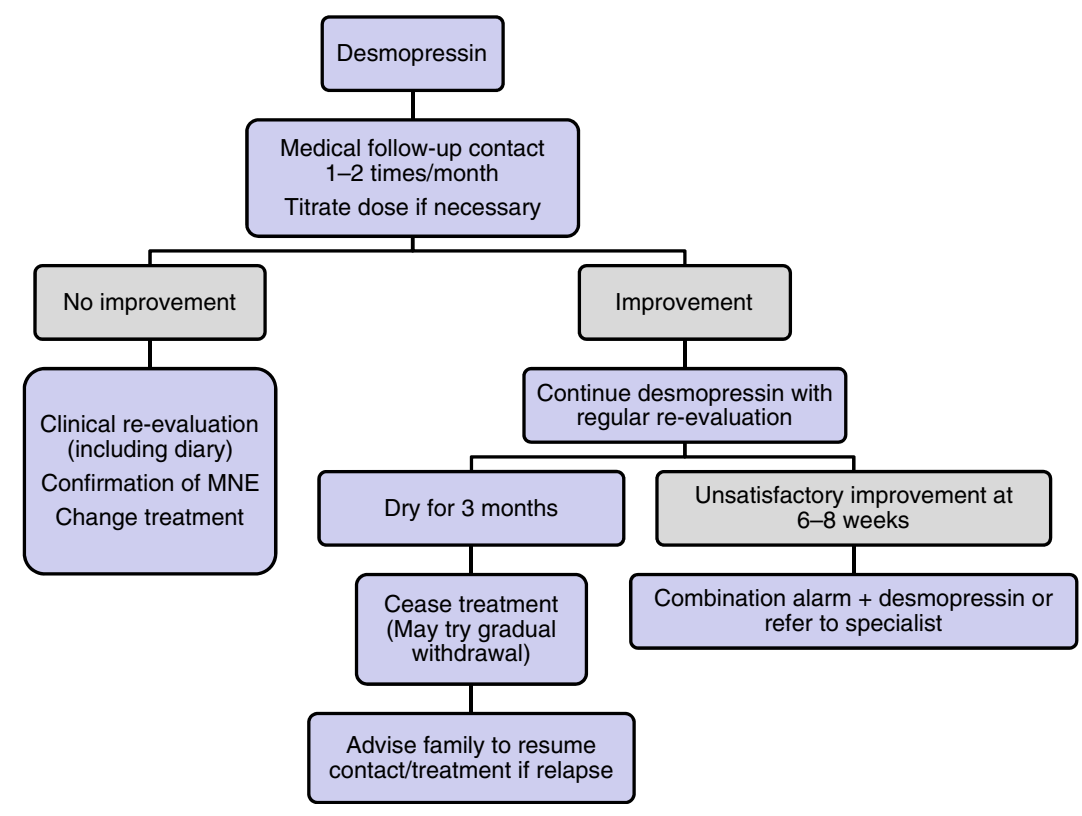

bedtime, and limitation of evening fluids can reduce treatment success [8]. Moreover, compliance is often overestimated, both by patients and MDs; therefore, it should be documented in a diary.

Patients who appear treatment-resistant should be advised of the importance of full adherence and asked if they have had any difficulty with complying with recommendations. It is important to cultivate an open atmosphere for discussion, since children may be reluctant to admit non-adherence if they feel their doctor is being judgmental.

\section{Non-response}

If children show no improvement with one first-line treatment, despite adherence, an alternative therapy should be tried.

\section{Follow-up}

Following successful treatment with either the alarm or desmopressin, patients should be advised to contact the clinic if relapse is experienced after discontinuation of 
therapy. If relapse occurs, further desmopressin, alarm, or combined therapy should be considered.

\section{Other strategies}

Arousal training (where a rapid response to the alarm is rewarded) may be beneficial, as demonstrated in the original study $[49,52]$. However, experience in clinical practice has had less than convincing results (resulting in a level 3, grade $\mathrm{C}$ recommendation from ICI); alarm alone is accepted best practice behavioral therapy.

A small number of alternative pharmacological approaches exist which may be considered if the patient is resistant to desmopressin and/or the alarm. Prescribing these should be restricted to specialized enuresis centers and not undertaken by MDs.

\section{Risk factors for treatment resistance and management strategies in these patients}

The most likely fundamental reason for not responding to alarm or desmopressin therapy is that the actual diagnosis is NMNE and not MNE. When a detailed history is obtained, the majority of these children have at least subtle daytime symptoms [30]. Therefore, the importance of taking a good clinical history, as presented in our CMT (Table 1), is paramount. If a patient is treatment-resistant and a bladder diary has not been completed, it is imperative this is undertaken or to refer the child to a specialty center as $\mathrm{OAB}$ and dysfunctional voiding may be present.

The subjective hallmark of $\mathrm{OAB}$ during the daytime is urgency. However, children with $\mathrm{OAB}$ may compensate by drinking very little during the day, therefore masking this symptom [62]. If OAB is suspected, a bladder diary should be repeated with a standardized (e.g., $25-30 \mathrm{ml} / \mathrm{kg} /$ day) fluid intake. In some children, symptoms of OAB are truly not present while awake, although there is marked detrusor overactivity during sleep [62]. Children with severe OAB/ reduced MVVs and those who are incontinent during the day may benefit from a period of bladder rehabilitation, such as scheduled voiding (with or without use of a programmable watch).

Children may have dysfunctional voiding (i.e., habitually contract the urethral sphincter during voiding), which is not identified by general screening for daytime symptoms. Dysfunctional voiding is common if there is recurrent urinary tract infection and constipation. If suspected and/or the patient is treatment-resistant, specialist referral for uroflowmetry and assessment of post-micturition residue is recommended. For children with suspected day and night detrusor overactivity, a combination of oxybutynin and desmopressin may be indicated (level 2, grade B).

Some patients with MNE may be resistant to desmopres$\sin$. This kind of patient is made of a heterogeneous group of subtypes and, as such, is beyond the scope of this approach; however, they can be generally subdivided into two subtypes - those with and without persistent NP.

Nocturnal urine volumes can give important information in the identification of patients with persistent NP. In patients with persistent NP, the following possibilities should be excluded before increasing the dose:

- Insufficient therapy compliance [50]

- No micturition before sleep

- Administration of drug $<1 \mathrm{~h}$ before last void before sleep

- Excessive fluid intake after or during the hour before desmopressin administration [8]

- Diabetes insipidus (renal/central, partial)

If the problem persists despite efforts to correct it, the patient is desmopressin-resistant and should be referred. Desmopressin-resistant NP is a well-known clinical entity [34]; several pathogenetic factors play a key role, including abnormalities in maximal concentrating capacity, nocturnal osmosis, sodium and calcium excretion, nycthemeral rhythm of prostaglandins, blood pressure, glomerular filtration rate, calciuria, diet factors, and/or sleep pattern [10, 36, $38,51]$. Recording of nocturnal urine volume can be repeated during treatment to see whether output is reduced or not.

The dose of desmopressin needed to reach maximum concentrating capacity may vary between patients. Therefore, assuming a bladder diary has been completed and NMNE properly excluded, treatment resistance may be due to inadequate dosing. Caution is mandatory with dose escalation; if children do not void in the morning, the dose should not be increased as this is suggestive of prolonged bioactivity.

Comorbidities associated with treatment resistance

Bowel habits are linked with lower urinary tract symptoms and urinary incontinence in particular. Constipation is a risk factor for enuresis and treatment resistance; it should be treated prior to devising a management plan for enuresis (see Box 3). Constipation is suspected in all patients with small volume fecal incontinence. Advice regarding sufficient fluid and dietary fiber intake, regular toilet habits (e.g., defecation every morning after breakfast), and potential use of laxatives should be provided.

Psychiatric conditions are additional risk factors for treatment resistance. There is an increasing number of reports regarding the beneficial effects of tricyclic antidepressants (e.g., imipramine) in selected subtypes of complicated and 
therapy-resistant children, such as those with attention deficit hyperactivity and sleep disorders. However, these subtypes need to be treated by specialists. Unless they are aware of, and know how to manage, its side effects, MDs should not prescribe imipramine, mainly because of its well-known potential for cardiotoxicity.

\section{Conclusions}

Enuresis is a common condition that can be very upsetting and disruptive to family life. The child's sleep architecture and cognition may be affected by repeated bladder signaling during the night. In many cases, MNE can be effectively treated by MDs through education that includes its causes and management, advice on eating, drinking and toileting habits, and prescription of appropriate treatments following a basic or enhanced evaluation strategy.

Our consensus opinion is based on the finding that evaluation (with/without voiding diaries) and an assessment of family preference and motivation can direct firstline treatment consisting of desmopressin (in particular the lyophilisate formulation) for patients with NP but without reduced MVV and an enuresis alarm for children with reduced MVV and normal nighttime urine output. Combination therapy (alarm + desmopressin) can also be considered for patients with both reduced MVV and NP or when children using an alarm awaken more than once during the night.

If one treatment does not work, another can be tried (assuming NMNE is thoroughly excluded using a bladder diary). The key message here is not to give up when attempting to devise an appropriate treatment strategy. If response cannot be achieved by the MD, with either strategy 1 or 2 , the child should be referred to a specialist to allow all possible therapeutic avenues to be explored.

\begin{abstract}
Acknowledgments Editorial assistance with this manuscript was provided by Caroline Loat, $\mathrm{PhD}$, ApotheCom ScopeMedical Ltd, and supported by Ferring Pharmaceuticals.
\end{abstract}

Disclosures Stuart Bauer and Paul Eggert have no conflicts of interest to declare. Soren Rittig has acted as a speaker for Ferring Pharmaceuticals and has participated in phase I, II, and III studies by Ferring, Astellas, and Pfizer. Johan Vande Walle has acted as a safety board advisor for Ferring International, advisor to Astellas on a study of solifenacin, and has participated in phase II and III studies by Novartis, AstraZeneca, Ferring International, Amgen, and MSD. Daniela Marschall-Kehrel has acted as consultant and speaker for Ferring Pharmaceuticals, Apogepha, Eli Lilly, and Pfizer and as consultant for Allergan, Astellas, Bayer, and Neurotech. Serdar Tekgul has been an investigator for anticholinergic trials for Pfizer, Sanofi, and Astellas and is former Chair of both the ICI Children's Committee (2008) and Pediatric Urology Guidelines (EAU/ESPU).
Open Access This article is distributed under the terms of the Creative Commons Attribution License which permits any use, distribution, and reproduction in any medium, provided the original author(s) and the source are credited.

\section{References}

1. Baeyens D, Lierman A, Roeyers H, Hoebeke P, Walle JV (2009) Adherence in children with nocturnal enuresis. J Pediatr Urol 5 (2):105-109

2. Berry AK (2006) Helping children with nocturnal enuresis: the wait-and-see approach may not be in anyone's best interests. Am J Nurs 106(8):56-63

3. Butler R, McKenna S (2002) Overcoming parental intolerance in childhood nocturnal enuresis: a survey of professional opinion. BJU Int 89(3):295-297

4. Butler RJ, Holland P, Robinson J (2001) Examination of the structured withdrawal program to prevent relapse of nocturnal enuresis. J Urol 166(6):2463-2466

5. Carskadon MA (2004) Sleep deprivation: health consequences and societal impact. Med Clin North Am 88(3):767-776

6. Committee for Medicinal Products For Human Use (2006) Reflection paper: formulations of choice for the paediatric population. London. Available at: www.emea.europa.eu. Accessed 19 Jan 2012

7. Culpepper L (2006) Secondary insomnia in the primary care setting: review of diagnosis, treatment, and management. Curr Med Res Opin 22(7):1257-1268

8. De Guchtenaere A, Raes A, Vande Walle C et al (2009) Evidence of partial anti-enuretic response related to poor pharmacodynamic effects of desmopressin nasal spray. J Urol 181(1):302-309

9. De Jonge DA (1973) Epidemiology of enuresis: a survey of the literature. In: Kolvin I, MacKeith RC, Meadow SR (eds) Bladder control and enuresis. Heinemann Medical Books, London

10. Dehoorne JL, Raes AM, Van LE, Hoebeke P, Vande Walle JG (2006) Desmopressin resistant nocturnal polyuria secondary to increased nocturnal osmotic excretion. J Urol 176(2):749-753

11. Dogan HS, Akpinar B, Gurocak S, Akata D, Bakkaloglu M, Tekgul S (2008) Non-invasive evaluation of voiding function in asymptomatic primary school children. Pediatr Nephrol 23(7):1115-1122

12. Ertan P, Yilmaz O, Caglayan M, Sogut A, Aslan S, Yuksel H (2009) Relationship of sleep quality and quality of life in children with monosymptomatic enuresis. Child Care Health Dev 35 (4):469-474

13. Evans JH (2001) Evidence based management of nocturnal enuresis. BMJ 323(7322):1167-1169

14. Evans J, Malmsten B, Maddocks A, Popli HS, Lottmann H (2011) Randomized comparison of long-term desmopressin and alarm treatment for bedwetting. J Pediatr Urol 7(1):21-29

15. Farhat W, McLorie GA, O’Reilly S, Khoury A, Bägli DJ (2001) Reliability of the pediatric dysfunctional voiding symptom score in monitoring response to behavioral modification. Can J Urol 8 (6):1401-1405

16. Fergusson DM, Horwood LJ, Shannon FT (1986) Factors related to the age of attainment of nocturnal bladder control: an 8-year longitudinal study. Pediatrics 78(5):884-990

17. Foxman B, Valdez RB, Brook RH (1986) Childhood enuresis: prevalence, perceived impact, and prescribed treatments. Pediatrics 77(4):482-487

18. Garber KM (1996) Enuresis: an update on diagnosis and management. J Pediatr Health Care 10(5):202-208

19. Glazener CM, Evans JH, Peto RE (2005) Alarm interventions for nocturnal enuresis in children. Cochrane Database Syst Rev (2): CD002911 
20. Hagglof B, Andren O, Bergstrom E, Marklund L, Wendelius M (1997) Self-esteem before and after treatment in children with nocturnal enuresis and urinary incontinence. Scand J Urol Nephrol Suppl 183:79-82

21. Hansen MN, Rittig S, Siggaard C et al (2001) Intra-individual variability in nighttime urine production and functional bladder capacity estimated by home recordings in patients with nocturnal enuresis. J Urol 166(6):2452-2455

22. Hellström AL, Hanson E, Hansson S, Hjälmås K, Jodal U (1990) Micturition habits and incontinence in 7-year-old Swedish school entrants. Eur J Pediatr 149(6):434-437

23. Hislop J, Arber S (2003) Sleepers wake! The gendered nature of sleep disruption among mid-life women. Sociology 37:695-711

24. Hjalmas K, Arnold T, Bower W et al (2004) Nocturnal enuresis: an international evidence based management strategy. J Urol 171(6 Pt 2):2545-2561

25. Hunsballe JM, Rittig S, Djurhuus JC (1995) Sleep and arousal in adolescents and adults with nocturnal enuresis. Scand J Urol Nephrol Suppl 173:59-60

26. Kamperis K, Hagstroem S, Rittig S, Djurhuus JC (2008) Combination of the enuresis alarm and desmopressin: second line treatment for nocturnal enuresis. J Urol 179(3):1128-1131

27. Longstaffe S, Moffatt ME, Whalen JC (2000) Behavioral and selfconcept changes after six months of enuresis treatment: a randomized, controlled trial. Pediatrics 105(4 Pt 2):935-940

28. Lottmann H, Froeling F, Alloussi S et al (2007) A randomised comparison of oral desmopressin lyophilisate (MELT) and tablet formulations in children and adolescents with primary nocturnal enuresis. Int J Clin Pract 61(9):1454-1460

29. Marschall-Kehrel D, Harms TW (2009) Structured desmopressin withdrawal improves response and treatment outcome for monosymptomatic enuretic children. J Urol 182(4 Suppl):2022-2026

30. National Institute for Health and Clinical Excellence (2010) Nocturnal enuresis: the management of bedwetting in children and young people. NICE, London

31. Neveus T, Eggert P, Evans J et al (2010) Evaluation of and treatment for monosymptomatic enuresis: a standardization document from the International Children's Continence Society. J Urol 183(2):441-447

32. Neveus T, Hetta J, Cnattingius S et al (1999) Depth of sleep and sleep habits among enuretic and incontinent children. Acta Paediatr 88(7):748-752

33. Nevéus T, von Gontard A, Hoebeke P et al (2006) The standardisation of terminology of lower urinary tract function in children and adolescents: report from the Standardisation Committee of the International Children's Continence Society (ICCS). J Urol 176 (1):314-324

34. Pugner K, Holmes J (1997) Nocturnal enuresis: economic impacts and self-esteem preliminary research results. Scand J Urol Nephrol Suppl 183:65-69

35. Raes A, Dehoorne J, Van LE, Hoebeke P, Vande WC, Vansintjan P et al (2007) Partial response to intranasal desmopressin in children with monosymptomatic nocturnal enuresis is related to persistent nocturnal polyuria on wet nights. J Urol 178(3 Pt 1):1048-1051

36. Rembratt A, Graugaard-Jensen C, Senderovitz T, Nørgaard JP, Djurhuus JC (2004) Pharmacokinetics and pharmacodynamics of desmopressin administered orally versus intravenously at daytime versus night-time in healthy men aged 55-70 years. Eur J Clin Pharmacol 60(6):397-402

37. Riley KE (1997) Evaluation and management of primary nocturnal enuresis. J Am Acad Nurse Pract 9(1):33-39

38. Rittig S, Jensen AR, Jensen KT, Pedersen EB (1998) Effect of food intake on the pharmacokinetics and antidiuretic activity of oral desmopressin (DDAVP) in hydrated normal subjects. Clin Endocrinol (Oxf) 48(2):235-241
39. Rittig S, Schaumburg HL, Siggaard C, Schmidt F, Djurhuus JC (2008) The circadian defect in plasma vasopressin and urine output is related to desmopressin response and enuresis status in children with nocturnal enuresis. J Urol 179(6):2389-2395

40. Robson L (2007) Bedwetting. Parkhurst Exch 15(12):66-67

41. Robson WL (2009) Clinical practice. Evaluation and management of enuresis. N Engl J Med 360(14):1429-1436

42. Rush EC, Chhichhia P, Kilding AE, Plank LD (2010) Water turnover in children and young adults. Eur J Appl Physiol 110:1209-1214

43. Sapi MC, Vasconcelos JS, Silva FG, Damião R, da Silva EA (2009) Assessment of domestic violence against children and adolescents with enuresis. J Pediatr (Rio J) 85(5):433-437

44. Schulpen TW (1997) The burden of nocturnal enuresis. Acta Paediatr 86(9):981-984

45. Sit FKY, Yeung CK, Sihoe JDY, Liu JWH (2003) Self-esteem before and after treatment in Chinese children with nocturnal enuresis and urinary incontinence: a qualitative approach. ICCS Abstracts 40

46. Tekgul S, Nijman R, Hoebeke P, Canning D, Bower W, von Gontard A (2009) Diagnosis and management of urinary incontinence in childhood. Report from the 4th International Consultation on Incontinence. Health Publication Ltd

47. Tekgul S, Riedmiller H, Gerharz E et al (2008) Guidelines on paediatric urology. European Society of Paediatric Urology [cited (2010) Nov 4]. Available at: http://www.uroweb.org/fileadmin/ user_upload/Guidelines/19\%20Paediatric\%20Urology.pdf

48. Theunis M, Van Hoecke E, Paesbrugge S, Hoebeke P, Vande Walle J (2002) Self-image and performance in children with nocturnal enuresis. Eur Urol 41(6):660-667

49. van Dommelen P, Kamphuis M, Van Leerdam FJ et al (2009) The short- and long-term effects of simple behavioral interventions for nocturnal enuresis in young children: a randomized controlled trial. J Pediatr 154:662-666

50. Van Herzeele C, Alova I, Evans J et al (2009) Poor compliance with primary nocturnal enuresis therapy may contribute to insufficient desmopressin response. J Urol 182(4 Suppl):20452049

51. van Kerrebroeck PE, Nørgaard JP (2009) Desmopressin for the treatment of primary nocturnal enuresis. Ped Health 3:311-327

52. van Londen A, van Londen-Barentsen MW, van Son MJ, Mulder GA (1993) Arousal training for children suffering from nocturnal enuresis: a 2 1/2 year follow-up. Behav Res Ther 31 (6):613-615

53. Vande Walle J, Vande Walle C, Van SP et al (2007) Nocturnal polyuria is related to 24-hour diuresis and osmotic excretion in an enuresis population referred to a tertiary center. J Urol 178 (6):2630-2634

54. Vande Walle JG, Bogaert GA, Mattsson S et al (2006) A new fast-melting oral formulation of desmopressin: a pharmacodynamic study in children with primary nocturnal enuresis. BJU Int 97 (3):603-609

55. von Gontard A (2009) Psychological aspects of urinary incontinence, enuresis and faecal incontinence. In: Abrams P, Cardozo L, Khoury S, Wein A (eds). Report from the 4th International Consultation on Incontinence. 4th edition. Health Publication Ltd, p. 760-792

56. Wagner WG, Johnson JT (1988) Childhood nocturnal enuresis: the prediction of premature withdrawal from behavioral conditioning. J Abnorm Child Psychol 16(6):687-692

57. Watanabe H, Kawauchi A, Kitamori T, Azuma Y (1994) Treatment system for nocturnal enuresis according to an original classification system. Eur Urol 25(1):43-50

58. Wolfish NM (2001) Sleep/arousal and enuresis subtypes. J Urol 166(6):2444-2447 
59. Woo SH, Park KH (2004) Enuresis alarm treatment as a second line to pharmacotherapy in children with monosymptomatic nocturnal enuresis. J Urol 171(6 Pt 2):2615-2617

60. Yeung CK, Diao M, Sreedhar B (2008) Cortical arousal in children with severe enuresis. N Engl J Med 358(22):2414-2415

61. Yeung CK, Sihoe JD, Sit FK, Bower W, Sreedhar B, Lau J (2004) Characteristics of primary nocturnal enuresis in adults: an epidemiological study. BJU Int 93(3):341-345
62. Yeung CK, Sit FK, To LK et al (2002) Reduction in nocturnal functional bladder capacity is a common factor in the pathogenesis of refractory nocturnal enuresis. BJU Int 90 (3):302-307

63. Yeung CK, Sreedhar B, Sihoe JD, Sit FK, Lau J (2006) Differences in characteristics of nocturnal enuresis between children and adolescents: a critical appraisal from a large epidemiological study. BJU Int 97(5):1069-1073 